\title{
The productivity of crop rotations on the eroded slope of ordinary chernozems depending on agricultural practices
}

\author{
Izida Ilyinskaya ${ }^{1 *}$, and Emma Gaevaya ${ }^{1}$ \\ ${ }^{1}$ FSBSI "Federal Rostov Agricultural Research Centre " 1 Institutskaya str., Rassvet village, Aksaysky district, Rostov region, 346735, \\ Russia
}

\begin{abstract}
Field experiments were carried out in the Rostov region on the slope of ordinary chernozems in the system of contour-strip organization of the territory in 2011-2020. The aim of the research was the development of agrotechnical methods (design of crop rotation, the method of basic tillage and the background of fertilizers), which ensure high productivity of crop rotations on the eroded slope of ordinary chernozems and the preservation of fertility. The experiment included three factors: the design of the crop rotation, the method of the main tillage, the background of mineral fertilizers. It was found that, on average, for the period of research, the level of mineral nutrition has the greatest influence on the productivity of the crop rotation (83.9\%), followed by the design of the crop rotation (14.9\%). The influence of basic tillage is estimated at only $1.2 \%$. It was found that the introduction of $20 \%$ of perennial grasses into the structure of crop rotation reduces soil washout by $19.5-27.7 \%$, and an increase in the proportion of perennial grasses to $40 \%$ - by $38.3-43.8 \%$. The use of chisel tillage reduces washout by $15.6-24.2 \%$, and with it the loss of humus. In the "C" crop rotation in all variants of the experiment, the humus content increased by 0.01 $0.03 \%$. It was revealed that the productivity of all the studied crop rotations changed under the influence of agrotechnical methods, reaching in the crop rotation " $\mathrm{C}$ " with $40 \%$ of perennial grasses and $60 \%$ of grain crops on average for the studied period the highest value of $3.53 \mathrm{t} /$ ha of grain units, which is $9.3 \%$ higher than in the "B" crop rotation and $17.3 \%$ higher than in the "A" crop rotation.
\end{abstract}

Key words: crop rotation, fertilizers, tillage, washout, humus, productivity.

\section{Introduction}

Crop rotation is the main organizational and agronomic category in agriculture, which is constantly being improved due to the complication of production tasks, the introduction of more advanced technologies for the cultivation of crops and the need for efficient use of manmade and natural resources and the possibility of preventing environmental complications. The most favorable alternation of crops is provided, the physical properties of the soil are improved, the system of tillage and the system of fertilizers are built more rationally in the crop rotation $[1,2,3]$.

The fight against erosion on sloping lands is an important part of the farming system, which ensures the preservation of soil fertility, the stability of crop yields, and environmental protection $[4,5]$. One of the ways for reducing and preventing water erosion on slope lands in the zone of ordinary chernozems is the contour-strip placement of agricultural crops, which involves the alternation of strips of erosion-resistant and unstable crops and agrophones.

The method of the main soil cultivation in arid regions under conditions of water erosion is of particular importance and largely determines the creation of optimal conditions for growing crops, the intensity of accumulation and retention of moisture, as well as the direction of soil erosion processes. In this regard, the development of the structure of crop rotations, which ensures the maximum productivity of crops on erosiondangerous slopes in combination with the use of effective soil protection measures based on field experiments acquires the relevance [5].

The main tillage is considered as an element of agricultural technologies, interacting with other elements (crop rotation, fallow share, predecessor, fertilizer, etc.) and agroecological conditions, which determine the choice of the method and depth of cultivation. Soil cultivation in arid conditions, as well as in places where water and wind erosion of soil is manifested, is of particular difficulty. Soil-protection technologies in erosion-hazardous agricultural landscapes on chernozem soils are based on non-moldboard plowing, which in grain and grain-fallow crop rotations is combined with plowing once or twice per rotation, increases labor productivity by 1.5 times when winter plowing, and reduces soil erosion by $2-4$ times $[6,7]$.

It should be noted that in recent decades, in studies aimed at protecting soils from erosion, insufficient attention has been paid to improving the strip and contourstrip placement of crops on slopes, which is an effective and relatively low-cost anti-erosion measures that reduce

\footnotetext{
* Corresponding author: izidaar@mail.ru
} 
erosion processes, exclude soil cultivation along the slope and contribute to the soil fertility increase $[2,4]$.

Soil erosion depends on many factors, including climate, soil, topography, culture and land use practices, control methods, and the size of the area under consideration [8].

Global warming has increased soil erosion by $2.1 \%$. The largest increase was shown by water erosion in semi-arid regions $(+7.4 \%)$ and wind erosion in arid regions $(+$ $3.2 \%)$ [9].

The purpose of the research is the development of agrotechnical methods (design of crop rotation, the method of basic tillage and fertilization) that ensure high productivity of crop rotations on the eroded slope of ordinary chernozems.

\section{Materials and methods}

The experiment is located on the slope of the southeastern exposition of the Bolshoi Log gully of the Aksai district of the Rostov region with a steepness of up to 3.5-4.0o with a total area of 26.5 hectares. The experience was laid in 1986 for the study of crop rotations, soil cultivation and fertilizers use on erosion-dangerous slopes. The experience includes three factors: 1 . Crop rotations; 2. Tillage. 3. Fertilizers.

Factor 1. The experiment studied three crop rotations with different erosion resistance: "A" - pure fallow 20\%, perennial grasses $0 \%$ (fallow, winter wheat, winter wheat, sunflower, spring barley); "B" - pure fallow $0 \%$, perennial grasses $20 \%$ (peas, winter wheat, sunflower, spring barley, sainfoin); "C" - pure fallow $0 \%$, perennial grasses $40 \%$ (corn for grain, winter wheat, spring barley with sainfoin over-sowing, sainfoin of the 2 nd year of life, sainfoin of the 3rd year of life).

Factor 2. Tillage system. The studies were carried out on two options for the main tillage in crop rotations: moldboard plowing (control) and soil protection plowing (chisel). Moldboard plowing for spring crops (for peas, corn for grain and sunflower - to a depth of $23-25 \mathrm{~cm}$, for spring barley - by $20-22 \mathrm{~cm}$, in a fallow field - to a depth of 27-30 cm). Chisel processing was carried out with a chisel plow PCh -2.5 , as the main cultivation to a depth of $27-30 \mathrm{~cm}$ in a fallow field, for row crops and peas - by 20-22 cm, for perennial grasses and spring barley - by 20 $22 \mathrm{~cm}$.

Factor 3. Fertilization system: "0" - zero level of fertilization (natural fertility). "1" - the first level of fertilizer application - $\mathrm{N}_{46} \mathrm{P}_{24} \mathrm{~K}_{30}$, "2" - the second level of fertilizer application $-\mathrm{N}_{84} \mathrm{P}_{30} \mathrm{~K}_{48} \mathrm{~kg}$ per 1 hectare of crop rotation area.

The counts, observations and mathematical processing of data of agricultural crops yield in crop rotations were carried out according to the method of the field experiment of B.A. Dospekhov and Gossortset [10,11].

The soil of the experimental site is ordinary chernozem, heavy loamy on loess-like loam, moderately eroded. According to our data, the average annual runoff is $20 \mathrm{~mm}$ (maximum $34.4 \mathrm{~mm}$ ). The average annual soil washout is $18.5 \mathrm{t} / \mathrm{ha}$ (maximum - $42 \mathrm{t} / \mathrm{ha}$ ). Thickness of the arable horizon is $25-30 \mathrm{~cm}, \mathrm{~A}+\mathrm{B}$ - from 40 to $90 \mathrm{~cm}$
- depending on washout. The porosity of the arable horizon is $61.5 \%$, of the subsoil - 54\%. HB - 33-35\%, wilting moisture $-15.4 \%$. The content of total nitrogen in the $0-30 \mathrm{~cm}$ layer is $0.14-0.16 \%$, mobile phosphates $15.7-18.2 \mathrm{mg} / \mathrm{kg}$, exchangeable potassium $282-337 \mathrm{mg} /$ $\mathrm{kg}$ of soil.

All agrotechnical work was carried out at the appropriate time in accordance with the calendar plan and technological maps of the cultivation of agricultural crops.

The climate of the Azov zone is arid, moderately hot, continental. The relative humidity of the air has a pronounced annual variation. Its lowest values are observed in July (50-60\%), the minimum on some days can be $25-30 \%$ and below. The arrival of PAR during the growing season is 3.5-4.0 billion kcal / ha [12]. The average long-term amount of precipitation is $492 \mathrm{~mm}$, their distribution in the agronomic assessment is often unfavorable. During the spring-summer period, 260-300 $\mathrm{mm}$ falls. The accumulation of moisture in the soil begins at the end of October and its maximum reserve is observed in early spring (from mid-March to early April). The sum of active temperatures is $3210-3400^{\circ}$. The average annual temperature is $8.8^{\circ} \mathrm{C}$. The frost-free period lasts $175-180$ days. Frequent phenomena are dry winds, dust storms of varying intensity.

\section{Results and Discussion}

The productivity of crop rotations is an integral indicator of their assessment, it depends on the design of the crop rotation, crop structure, natural conditions (soil and climatic) and man-made factors. The design of crop rotations, their different degrees of protection from erosion processes, biological characteristics and capabilities of crops in combination with the emerging conditions of moisture supply and the technology of cultivation of crops determined the level of their productivity by years.

Soil fertility on erosion-hazardous slopes consists of several indicators, one of which is the amount of soil washout. The greatest losses as a result of washout were noted in crop rotation "A", which has $20 \%$ of pure fallow in the crop structure (5.0-6.0 t/ ha). With an increase of the perennial grasses share in the structure of crops, soil erosion decreases in the "B" crop rotation with $20 \%$ of perennial grasses - by $19.5-27.7 \%$, in the "C" crop rotation with $40 \%$ of perennial grasses - by $38.3-43.8 \%$ in comparison with the grain-cultivated crop rotation.

Chisel tillage protects the soil and reduces soil loss as well as the loss of basic nutrients by $15.6-24.2 \%$ (Table 1 ).

The coefficient of susceptibility to erosion processes (Ke) shows the intensity of soil washout depending on the design of crop rotation and tillage and represents the ratio of the actual soil washout to the maximum allowable (3.5 $\mathrm{t} / \mathrm{ha}$ ) [13]. With an increase of the perennial grasses share in the structure of crop rotation, it decreases by more than one and a half times, which indicates the stability of crop rotations to the development of erosion processes. 
Table 1. Soil washout depending on the design of crop rotation and the tillage method

\begin{tabular}{|c|c|c|c|}
\hline \multirow{2}{*}{$\begin{array}{c}\text { Crop } \\
\text { rotation }\end{array}$} & $\begin{array}{c}\text { Tillage } \\
\text { method }\end{array}$ & $\begin{array}{c}\text { Flushing, } \\
\mathrm{t} / \mathrm{ha}\end{array}$ & $\begin{array}{c}\text { Coefficient of } \\
\text { exposure to } \\
\text { erosion } \\
\text { processes, (Ke) }\end{array}$ \\
\hline \multirow{2}{*}{$\mathrm{A}$} & Chisel & $5.0 \pm 1.1$ & 1.4 \\
\cline { 2 - 4 } & Mold board & $6.0 \pm 1.2$ & 1.7 \\
\hline \multirow{2}{*}{$\mathrm{B}$} & Chisel & $3.6 \pm 0.7$ & 1.0 \\
\cline { 2 - 4 } & Mold board & $4.8 \pm 0.9$ & 1.4 \\
\hline \multirow{2}{*}{$\mathrm{C}$} & Chisel & $2.8 \pm 0.5$ & 0.8 \\
\cline { 2 - 4 } & Mold board & $3.7 \pm 0.7$ & 1.1 \\
\hline
\end{tabular}

One of the indicators of the productivity of arable land is the content of humus. Monitoring the dynamics of humus over a ten-year period revealed the following regularities: the change in the percentage of humus depends on soil washout and on the amount of fertilizers applied (Table 2).

Table 2. Change in humus content depending on the design of the crop rotation, the level of mineral nutrition and the method of basic tillage $\%$

\begin{tabular}{|c|c|c|c|c|c|c|c|}
\hline \multirow[b]{3}{*}{ Year } & \multirow{3}{*}{$\begin{array}{l}\text { Lev } \\
\text { el of } \\
\text { fertil } \\
\text { izati } \\
\text { on }\end{array}$} & \multicolumn{6}{|c|}{ Crop rotation } \\
\hline & & \multicolumn{2}{|c|}{$\mathrm{A}$} & \multicolumn{2}{|c|}{$\mathrm{B}$} & \multicolumn{2}{|c|}{$\mathrm{C}$} \\
\hline & & $\begin{array}{c}\text { Chis } \\
\text { el }\end{array}$ & $\begin{array}{c}\text { Mol } \\
\mathrm{d} \\
\text { boar } \\
\mathrm{d}\end{array}$ & $\begin{array}{c}\text { Chis } \\
\text { el }\end{array}$ & $\begin{array}{c}\text { Mol } \\
\mathrm{d} \\
\text { boar } \\
\mathrm{d}\end{array}$ & $\begin{array}{c}\text { Chis } \\
\text { el }\end{array}$ & $\begin{array}{c}\text { Mol } \\
\mathrm{d} \\
\text { boar } \\
\mathrm{d}\end{array}$ \\
\hline \multirow{3}{*}{2011} & 0 & 3.60 & 3.59 & 3.67 & 3.68 & 3.70 & 3.69 \\
\hline & 1 & 3.68 & 3.68 & 3.82 & 3.78 & 3.88 & 3.87 \\
\hline & 2 & 3.94 & 3.94 & 4.08 & 4.07 & 4.10 & 4.10 \\
\hline \multirow{3}{*}{2020} & 0 & 3.59 & 3.58 & 3.66 & 3.65 & 3.72 & 3.69 \\
\hline & 1 & 3.67 & 3.65 & 3.79 & 3.78 & 3.90 & 3.88 \\
\hline & 2 & 3.96 & 3.95 & 4.10 & 4.09 & 4.13 & 4.12 \\
\hline \multirow{3}{*}{$\begin{array}{c}\text { Growt } \\
\mathrm{h}(+) / \\
\text { losses( } \\
-)\end{array}$} & 0 & $\begin{array}{c}- \\
0.01\end{array}$ & $\begin{array}{c}- \\
0.01\end{array}$ & $\begin{array}{c}- \\
0.01\end{array}$ & $\begin{array}{c}- \\
0.03\end{array}$ & 0.02 & 0.01 \\
\hline & 1 & $\begin{array}{c}- \\
0.01\end{array}$ & $\begin{array}{c}- \\
0.03\end{array}$ & $\begin{array}{c}- \\
0.03\end{array}$ & $\begin{array}{c}- \\
0.01\end{array}$ & 0.01 & 0.01 \\
\hline & 2 & 0.02 & 0.01 & 0.02 & 0.02 & 0.03 & 0.02 \\
\hline
\end{tabular}

Perennial grasses not only protect the erosiondangerous slope from the development of erosion processes, but also contribute to the accumulation of humus in the soil. A tendency for the loss of humus from $0.01 \%$ to $0.03 \%(\mathrm{P}<0.05)$ was observed on the variants of natural fertility and with the application of fertilizers with the rate of $\mathrm{N} 46 \mathrm{P} 24 \mathrm{~K} 30$ on the variant of the first level in the crop rotations "A" and "B". In the "C" crop rotation, which has $40 \%$ of perennial grasses in the structure of sown areas, the humus content increased by $0.01-0.02 \%$ in the same experimental variants. An increase in the fertilizer application rate by one and a half times in the second-level variant led to a significant increase in the humus content $(\mathrm{P}>0.05)$. The use of chisel tillage stimulated a slight increase in the organic carbon content in the soil $(\mathrm{P}<0.05)$.

A decrease in the amount of atmospheric precipitation on average for the growing season 2011-2020 with an increase in the sum of temperatures led to a decrease in the degree of moisture supply of the territory according to the hydrothermal coefficient of G. T. Selyaninova (HTC) to 0.74 against the long-term average value of 0.85 , that is, by $13 \%$ (Fig. 1) [12].

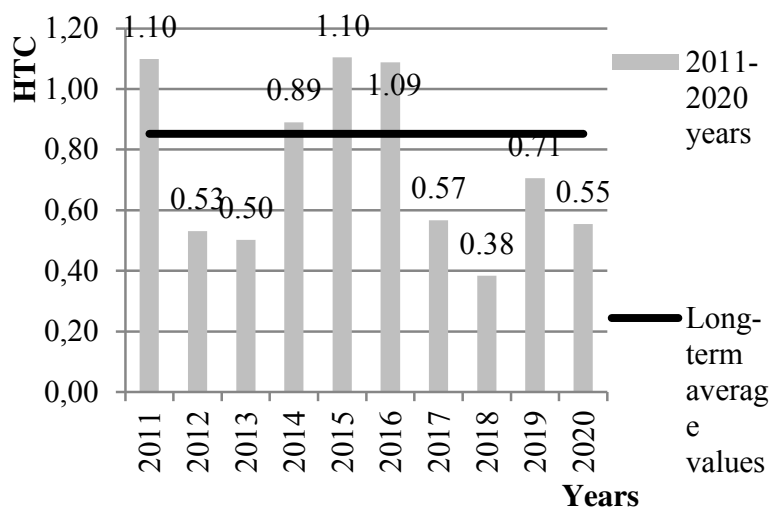

Fig. 1. The values of the hydrothermal coefficient for the period 2011-2020 years

The productivity of crop rotations changed under the influence of its structure, rates of mineral fertilizers and methods of basic soil cultivation over the years of research (Table 3).

Table 3. Average productivity of crop rotations on an eroded slope depending on agrotechnical factors for 2011-2020, t of grain units

\begin{tabular}{|c|c|c|c|c|c|c|c|}
\hline \multirow[t]{2}{*}{ 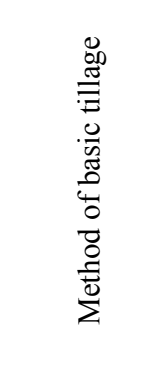 } & \multirow[t]{2}{*}{ 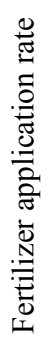 } & \multicolumn{3}{|c|}{ Crop rotation } & \multirow[t]{2}{*}{ 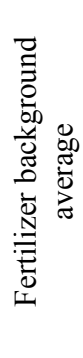 } & \multicolumn{2}{|c|}{ 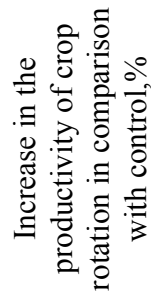 } \\
\hline & & A & B & C & & B & $\mathrm{C}$ \\
\hline \multirow{3}{*}{ Chisel } & 0 & 2.50 & 2.62 & 2.93 & 2.68 & 4.8 & 17.2 \\
\hline & 1 & 3.21 & 3.31 & 3.53 & 3.35 & 3.1 & 9.9 \\
\hline & 2 & 3.63 & 3.70 & 3.96 & 3.76 & 1.9 & 9.1 \\
\hline $\begin{array}{l}\text { Average for } \\
\text { tillage }\end{array}$ & & 3.11 & 3.21 & 3.47 & 3.26 & 3.2 & 11.6 \\
\hline \multirow{3}{*}{$\begin{array}{l}\text { Mold board } \\
\text { (the } \\
\text { control*) }\end{array}$} & 0 & 2.51 & 2.70 & 3.06 & 2.75 & 7.6 & 21.9 \\
\hline & 1 & 3.17 & 3.31 & 3.64 & 3.37 & 4.6 & $\begin{array}{ll}14.8 \\
\end{array}$ \\
\hline & 2 & 3.56 & 3.72 & 4.06 & 3.78 & 4.5 & 14.0 \\
\hline $\begin{array}{l}\text { Average for } \\
\text { tillage }\end{array}$ & & 3.08 & 3.24 & 3.59 & 3.30 & 5.2 & 16.5 \\
\hline $\begin{array}{l}\text { Average for } \\
\text { crop } \\
\text { rotations }\end{array}$ & & 3.01 & 3.23 & 3.53 & 3.26 & 7.3 & 17.3 \\
\hline
\end{tabular}

$\mathrm{HCP} 05=0.2 \mathrm{t} /$ ha; crop rotation and nutritional level $0.18 \mathrm{t} / \mathrm{ha}$; tillage $0.43 \mathrm{t} /$ ha.

*Note. The productivity of the crop rotation "A" was taken as control.

So, crop rotation "B" showed higher productivity than the control crop rotation "A" with $20 \%$ of pure fallow at the natural background of nutrition on average by 4.7 $7.8 \%$, at the medium level of nutrition - by $2.9-4.6 \%$, and it increased by $2.1-4.6 \%$ at the high background of fertilization for moldboard basic tillage. In crop rotation " $\mathrm{C}$ " under the same conditions on a natural background of nutrition the highest productivity was obtained, which exceeds the control by $16.9-22.0 \%$, at the medium nutritional level - by $9.9-15.0 \%$ and at the high nutritional level - by $9.3-14.1 \%$. 
Application of the medium fertilizer rate increased the productivity of crop rotation "A" by an average of 28.4$26.3 \%$, and the high rate - by $45.2-41.8 \%$; for crop rotation "B" - by $26.3-22.3 \%$ and by $41.2-37.8 \%$; \% and for crop rotation "C" - by $20.5-19.0 \%$ and $35.2-32.7 \%$.

The increase in productivity of crop rotation "B" with chisel tillage was on average $3.2 \%$ and crop rotation " $\mathrm{C}$ " $-11.6 \%$, while it increased to 5.2 and $16.5 \%$, respectively with moldboard cultivation.

The main tillage, all other things being equal, slightly changed the productivity of crop rotations, within the limits of the least significant difference.

The highest productivity was in the " $\mathrm{C}$ " crop rotation, averaging $3.06 \mathrm{t} /$ ha of grain units at the natural level of fertility, 3.53-3.64 $\mathrm{t} / \mathrm{ha}$ of grain units at the medium nutritional level, and 3.96-4.06 $\mathrm{t} /$ ha of grain units with the high rate of fertilizers. At the same time, significant differences at the 5\% significance level were revealed only when comparing productivity values depending on the design of crop rotation and the level of mineral nutrition (Fig. 2).

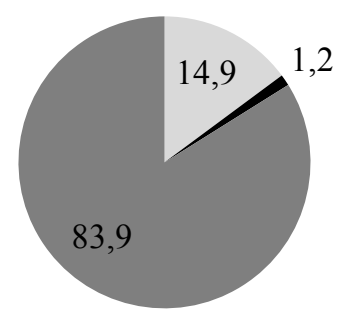

The predecessor in the crop rotation

- Method of tillage

The level of mineral nutrition

Fig. 2. The share of participation of various factors in the productivity of crop rotations, $\%$

The degree of influence of the tillage factor on the effective trait is $1.2 \%$, which is insignificant. The effect of the fertilizer factor $(83.9 \%)$ and the design of crop rotations $(14.9 \%)$ reaches significant values, which indicates that they have a significant impact on the productive trait.

In general, the productivity of crop rotation "B" with chisel tillage increases by $4.7-2.1 \%$, and with moldboard tillage by $7.8-4.6 \%$ compared to the same indicator in the control crop rotation "A", however, with an increase in fertilizer rate, the intensity of productivity growth decreases almost twice, which is due to a factor that is at a minimum. The same tendency was noted in the "C" crop rotation, however, the growth of productivity here was 34 times higher due to the nutrition level increase. The least soil erosion was noted in this crop rotation. The application of fertilizers with medium and increased rate made it possible to obtain an increase in humus, which increased the productivity of this crop rotation.

\section{Conclusion}

It was found that the level of mineral nutrition on average over 10 years of research has the greatest influence on the productivity of the crop rotation $(83.9 \%)$, followed by the design of the crop rotation (14.9\%). The influence of basic tillage is estimated at only $1.2 \%$. The introduction of $20 \%$ of perennial grasses into the crop rotation structure (crop rotation "B") reduces soil washout by $19.5-27.7 \%$, and the increase of the perennial grasses share to $40 \%$ (crop rotation "C") - by 38.3-43.8\%. The use of chisel tillage reduces washout by $15.6-24.2 \%$, and with it the loss of humus decreases. In the " $\mathrm{C}$ " crop rotation in all variants of the experiment, the humus content increased by 0.01 $0.03 \%$. It was revealed that the productivity of all the studied crop rotations changed under the agrotechnical methods influence, reaching in the crop rotation " $\mathrm{C}$ " with $40 \%$ of perennial grasses and $60 \%$ of grain crops on average for the study period the highest value of $3.53 \mathrm{t} /$ ha of grain units, which is $9.3 \%$ higher than in crop rotation "B" and $17.3 \%$ higher than in crop rotation "A".

The work was carried out within the framework of the State tasks of FSBSI «Federal Rostov Agricultural Research Centre» on topic No. 0710-2019-0026.

\section{References}

1. I. N. Listopadov. Crop rotations of the southern regions. - Rostov-on-Don. - 275 p. (2005)

2. Zonal farming systems of the Rostov region (for the period 2013-2020). - GNU Donskoy Research Institute of Agriculture. Part 1. - Rostov-on-Don: MOKHiP RO. - 295 p. (2012)

3. N.N. Dubachinskaya, Agriculture, 6.P. 32. (2013)

4. E.V. Poluektov, E.P. Lugantsev Soil protection systems in landscape agriculture. - Rostov-on-Don: Publishing house of SKNTs VSh, - 208 p. (2005)

5. A. N. Kashtanov, Agriculture. 3. - S. 10-12. (2000)

6. G.N. Cherkasov, I.G. Pykhtin, A.G. Rozhkov et al. Scientific bases for the formation of resource-saving technologies for the cultivation of agricultural crops in landscape agriculture - Kursk: GNU VNIIZ and ZPE. - 35 p. (2004)

7. V.M. Novikov, Agriculture. 1. - S. 24-25. (2008)

8. M.J.M. Romkens, K. Helming, S.N. Prasad, Catena. 46 (2-3). - R. 103-123. (2002)

9. X. Ma, Ch. Zhao, J. Zhu, Catena. 200. - 105129. (2021)

10. B.A. Dospekhov Field experiment technique (With the basics of statistical processing of research results). - Ed. 4th rev. and add. M.: Kolos. - 416 p. (1979)

11. M. A. Fedin Methodology of State Variety Testing of Agricultural Crops. - M.: Publishing house of the Ministry of Agriculture of the USSR. - 263 p. (1985)

12. Agroclimatic resources of the Rostov region. - L.: Hydrometeoizdat. - 250 p. (1972)

13. E.V. Poluektov Soil erosion on the Don and measures to combat it. Rostov-on-Don - Don Zonal Research Institute of Agriculture. - 160 p. (1984) 